\title{
EFECTOS DE LA ACCIÓN ANTRÓPICA EN SISTEMAS HIDROMORFOLÓGICOS SEMIÁRIDOS: LA CUENCA DE LA RAMBLA DE LAS CULEBRAS EN ÁGUILAS (MURCIA)
}

\author{
Human impact on semiarid hidromorphological \\ systems: basin of La Rambla \\ de las Culebras in Águilas (Murcia)
}

Carmelo Conesa García, Rafael García Lorenzo y Pedro Pérez Cutillas ${ }^{1}$

Recibido: 31/01/2013 Aceptado: 3/04/2013

Resumen. El presente artículo tiene como objeto mostrar las modificaciones impuestas por el hombre en uno de los sistemas hidromorfológicos semiáridos más activos y peligrosos de la región de Murcia: la cuenca de la Rambla de las Culebras, Águilas (Murcia). Tras una descripción somera de las condiciones ambientales que controlan el funcionamiento hidromorfológico de esta cuenca, se analizan los rasgos del sistema de ramblas del Renegado y de las Culebras, en particular su régimen hidráulico y los aportes torrenciales asociados a su elevada capacidad de transporte. A continuación, se estudian los cambios morfológicos inducidos por la acción antrópica en el conjunto de la cuenca, entre ellos los ocasionados por la reactivación geomorfológica de las laderas, así como los observados en la red de drenaje, cauces y lechos de inundación.

Palabras clave: Sistema hidromorfológico semiárido, cauces efímeros, Ilanura de inundación acción del hombre, cambios morfológicos, Rambla de las Culebras, Águilas.

Abstract. This paper attempts to show the changes imposed by human activities in one of the most dangerous and active semiarid hydromorphologica systems in the region of Murcia: Basin of Rambla de las Culebras (Águilas, Murcia). A short description show the environmental conditions that control the behavior of this hydromorphological basin, and are analyzed the properties of the systems of ramblas del Renegado y de las Culebras, in particular hydraulic conditions and torrential inputs associated caused by high transport capacity. Finally, we study the morphological changes induced by anthropic action in the whole basin, including those caused by hillsides geomorphological reactivation and those observed in the drainage network,streambed and floodplain.

Key words: Semiarid hydromorphological system, ephemeral channels, floodplain, human action, morpholoaical adiustments, Culebras Rambla. Áquilas.

(') Universidad de Murcia. Departamento de Geografía. Santo Cristo, 1. Facultad de Letras. Campus Universitario de La Merced. 30001 (Murcia). rafaelgl@um.es; cconesa@um.es ; pedrope@um.es El presente artículo se ha realizado en el marco del Proyecto RIFLUTME "Procesos de riesgos con origen natural asociados a sistemas fluviales de régimen torrencial mediterráneo. Aplicación a la franja costero meridional de la Región de Murcia". Referencia 02955/P//05. Financiado por la Fundación SENECA, Agencia de Ciencia y Tecnología de la Región de Murcia. 


\section{INTRODUCCIÓN}

Como es sabido, las regiones semiáridas se caracterizan por precipitaciones escasas muy irregulares y valores altos de evapotranspiración, que hacen de ellas medios especialmente sensibles a los procesos de erosión y desertificación (Le Houérou, 1996). En estos ambientes, en los que se encuadra el área de estudio, la sequía estival es especialmente larga y acusada, mientras que en otoño aumenta de forma apreciable la pluviosidad, normalmente con carácter torrencial (Millán et al., 2005). Las abultadas escorrentías generadas por lluvias de singular intensidad modelan y modifican de forma significativa los sistemas hidromorfológicos de cursos de agua efímeros, que en poco tiempo pasan de estar completamente secos a alcanzar grandes caudales pico y altas tasas de transporte sólido (Coppus \& Imeson 2002).

Un rasgo común en muchos de estos cursos esporádicos, motivado quizá por la inexistencia de un régimen permanente, es la falta de uniformidad morfológica de su cauce, a menudo sujeto a cambios de sección y ajustes de la geometría hidráulica (Conesa García, 2003; 2010). En casos extremos, los ajustes implican cambios hidromorfológicos globales que, dependiendo del caudal de avenida, convierten determinados tramos del cauce en elementos migratorios a lo largo del trazado fluvial (Oostwoud et al., 2000; Hooke \& Mant, 2000). Los sistemas torrenciales de las ramblas del Renegado y de las Culebras se caracterizan por la presencia de áreas fuentes de sedimento muy activas en zonas de cabecera, cauces de transferencia relativamente cortos con una rápida transmisión de flujo y cambios bruscos en el trazado capaces de provocar repentinas dispersiones y depósitos de los materiales en arrastre. Pero la dinámica de estos sistemas hace que sus efectos morfológicos se puedan reproducir en cualquier parte de la cuenca y a diferentes escalas, lo que le confiere a cada tramo del sistema una independencia propia y una capacidad de autoajuste (Poesen et al., 2003). Los procesos geomórficos, así considerados, adquieren una elevada capacidad de retroalimentación y sinergia que hacen difícil su estudio si no es abarcado de forma integral (Graf, 1988; Qu \& Duffy, 2007).

La acción antrópica puede modificar, interrumpir y, en algunos casos, desconectar la dinámica natural de los procesos hidrológicos, alterando los elementos naturales de estos sistemas ya de por si frágiles. Con frecuencia, los efectos de la intervención humana se dejan notar no solo en los cauces (Ortega et al., 2009), sino también de forma indirecta a través de los cambios sufridos en las áreas de influencia de su sistema de drenaje, por la trasformación de los usos del suelo (Domingo et al., 2001), alteración de la cubierta vegetal (Puigdefabregas et al., 1999), construcción de infraestructuras hidráulicas (Jordan et al., 2010) o la captación de recursos hídricos subterráneos (Khazaei et al., 2003). Cualquier alteración que afecte al sistema conlleva el encade- namiento de respuestas, no siempre predecibles, sobre otros mecanismos hidrológicos y geomorflógicos tanto a nivel espacial como temporal (Nachtergaele \& Poesen, 2002). Cuando estos espacios resultan altamente dañados por soportar fuertes presiones antrópicas, las acciones de restauración pueden constituir una alternativa adecuada para su recuperación (Chin \& Gregory, 2001; Kondolf, 2005). Para el correcto funcionamiento de estos ecosistemas, y como base de cualquier proceso de restauración, es necesario mantener un equilibrio hidrogeomorfológico dinámico (Rozin \& Schick, 1996). Tarea que no se presenta sencilla debido a la dificultad científica y técnica del trabajo en este tipo de sistemas fluviales, y sobre todo porque hay que vencer enormes inercias sociales y administrativas, así como graves deficiencias en su marco legal (Shields et al., 2003). Para la perfecta adecuación y sostenibilidad de estos sistemas hidromorfológicos es necesario dotar de forma suficiente el espacio y tiempo adecuados a su escala estructural y funcional. Si no se concede a estos cauces el espacio necesario, será imposible compatibilizar la conservación de la dinámica fluvial con los usos humanos y la sostenibilidad de dichos espacios (Downs \& Gregory, 2004).

Con este estudio se pretende mostrar la intensa transformación, y en buena parte alteración, de un sistema fluvial semiárido particularmente activo, sometido a una fuerte presión antrópica: la cuenca de la Rambla de las Culebras, Águilas (Murcia). Sus resultados pueden constituir un importante complemento para la evaluación final del riesgo de avenidas en la zona, puesto que se proporcionan datos sobre capacidad de transporte de sedimentos que influyen en la magnitud de sus efectos. Se trata de un sistema de drenaje efímero profundamente afectado por la acción del hombre (invasión del lecho de inundación y del propio cauce por invernaderos, construcción de motas, escolleras, muros de derivación, encauzamientos, etc.), que en las últimas décadas ha empeorado su calidad hidromorfológica e incrementado su peligrosidad de forma ostensible.

\section{2. ÁREA DE ESTUDIO Y CARACTERÍSTICAS AMBIENTALES}

La cuenca de la Rambla de las Culebras, a pesar de su escasa extensión $\left(25,8 \mathrm{Km}^{2}\right)$, muestra una importante actividad geomorfológica asociada a la fragilidad impuesta por sus condiciones ambientales. Forma parte de todo un sistema de ramblas litorales que, a lo largo de la franja sur de la Región de Murcia, drenan directamente al mar Mediterráneo. Dicha franja costera se enmarca dentro de las Cordilleras Béticas y más concretamente en el sector suroccidental de la Zona Bética en sentido estricto. Dentro de este ámbito, las sierras litorales (Almagrera, Almenara, Algarrobo, Cartagena, etc.) dibujan un gran cordón montañoso generalmente próximo 


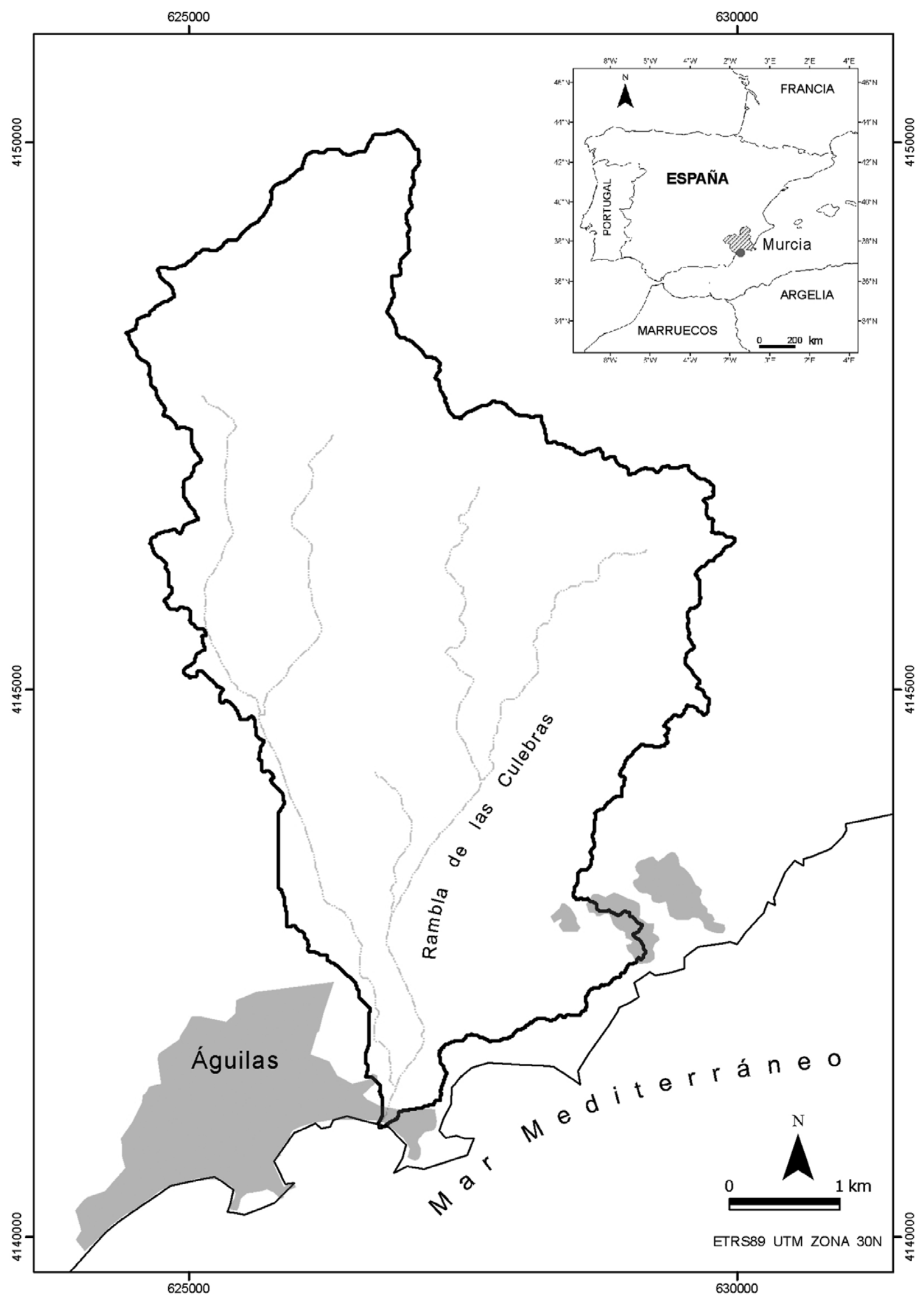

\ Figura 1. Mapa de situación de la cuenca de la Rambla de las Culebras en el contexto regional y peninsular. 


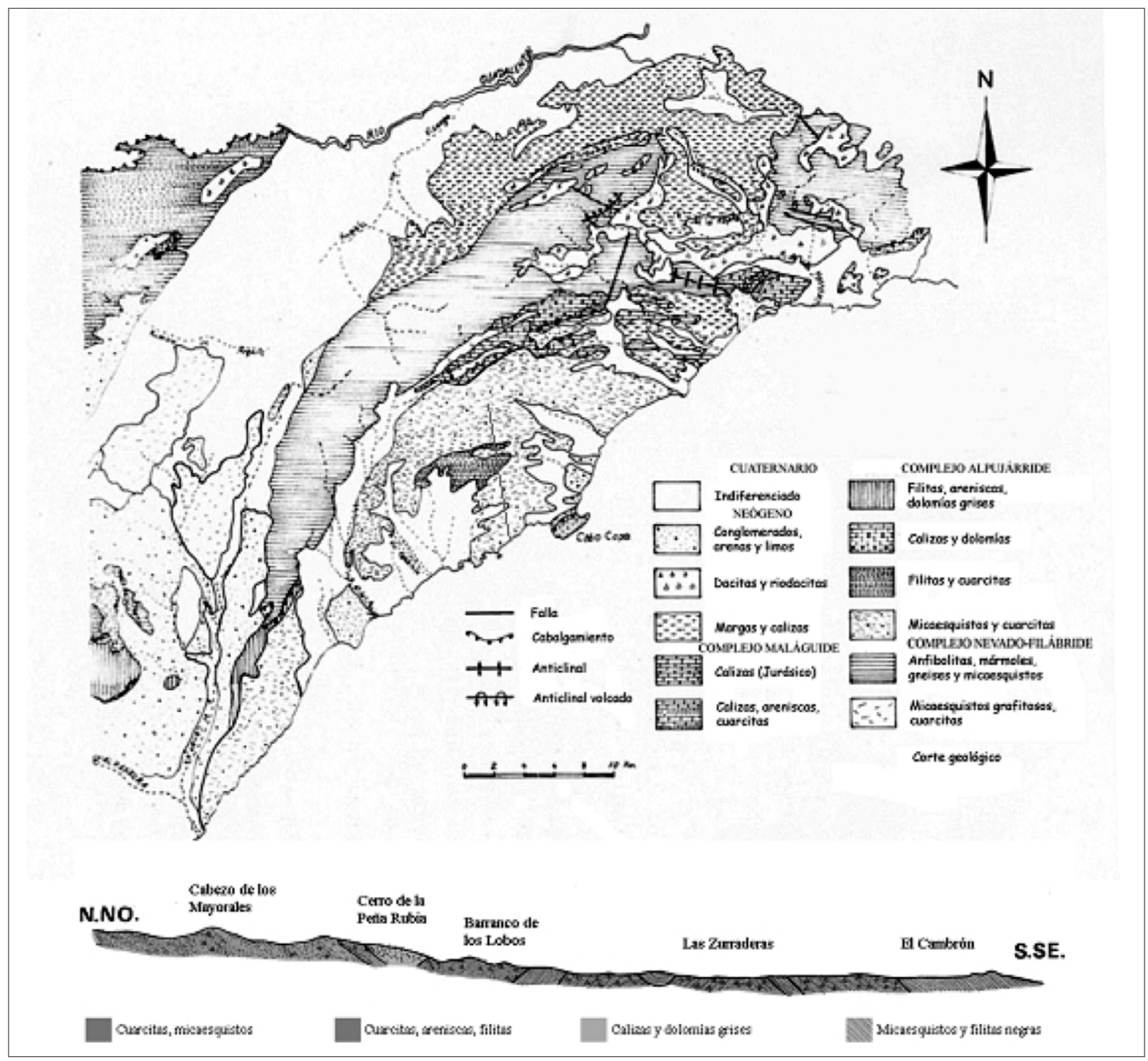

A Figura 2. Croquisgeológico regional y corte geológico Cabezo de los Mayorales-El Cambrón (Hoja 997 del Mapa Geológico de España, 1:50.000, Serie Magna (IGME, 1974).

a la línea de costa, al pie del cual se desarrollan las actuales depresiones litorales.

Al igual que el resto de cuencas costeras meridionales, la cuenca de la Rambla de las Culebras tiene una red de drenaje dendrítica en cabecera, fuertes pendientes y un claro carácter torrencial. Los recursos hidrogeológicos del área no son muy abundantes, debido ciertas particularidades litológicas y estructurales. En las series paleozoicas predominan las rocas metamórficas poco permeables, especialmente las pizarras y esquistos. En ellas la disposición laminar de la estructura de las rocas dificulta la filtración de las aguas, que tienden a deslizarse por escorrentía. La extrema aridez y las altas tasas de insolación de estas tierras costeras imponen el desarrollo de una vegetación natural muy particular. La asociación más común en esta zona, con especial desarrollo en las laderas de Cabo Tiñoso, es la de espino negro (Rhamnuslycioides) y palmito (Chamaeropshumilis).

\section{RASGOS GEOLÓGICOS Y TOPOGRÁFICOS}

El área de estudio se sitúa dentro del dominio bético costero o zona interna de las Cordilleras Béticas, compuesta principalmente por materiales antiguos y metamórficos. En la Región de Murcia este dominio incluye las sierras meridionales y prelitorales, extendidas al sur de las sierras subbéticas. Se caracteriza por facies paleozoicas, mantos de corrimiento y un metamorfismo regional alpino, que permiten definir cuatro grandes complejos litoestratigráficos: Nevado-Filábride, Ballabona-Cucharón, Alpujárride y Ma- 


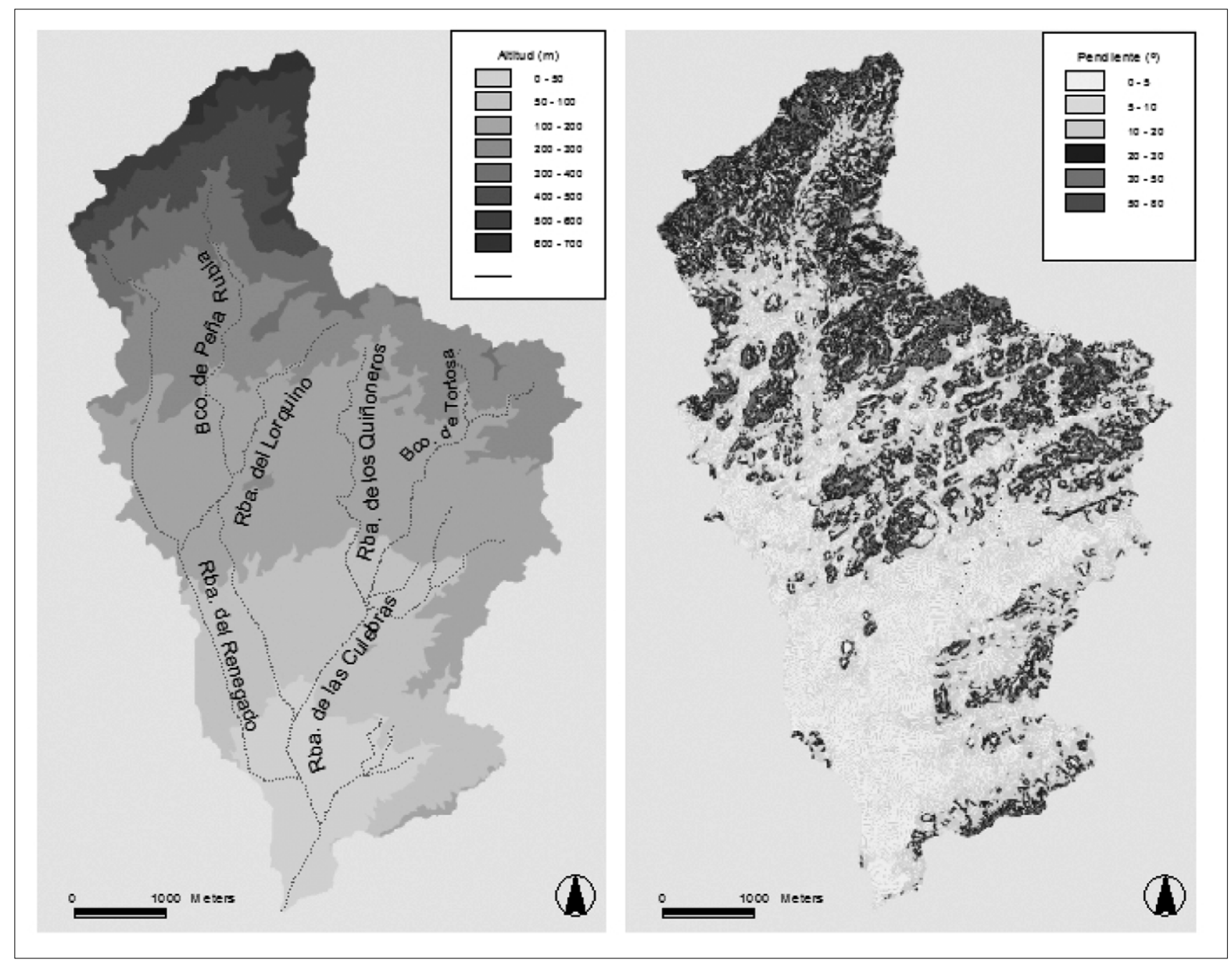

Figura 3. Distribución espacial de altitudes y pendientes relativas.

láguide. De ellos sólo dos están bien representados en la cuenca de las Culebras: el Nevado-Filábride y el Alpujárride.

Los grandes complejos estructurales coinciden en la zona con las alineaciones orográficas más importantes dispuestas en forma de arcos (Sánchez et al., 1979). El Nevado Filábride, zona más interna del Bético s.s., forma los relieves más septentrionales del área (Sierra de Almenara). El Alpujárride representa una unidad tectónica superpuesta al anterior, en la que pueden diferenciarse dos series: Paleozoico Inferior (micaesquistos, esquistos negros, cuarcitas) y Superior (filitas, areniscas, cuarcitas). A partir del Mioceno se produce una distensión generalizada que implica diversos reajustes tectónicos y la individualización de depresiones limitadas por fallas, en su mayoría de dirección N-S (Vera, Águilas, sector de Cabo Cope, Calnegre-Bolnuevo, Mazarrón), que fueron objeto de un importante relleno neógenocuaternario (Lillo Carpio, 1988).

El corte geológico representado en la figura 2 muestra un transecto de más de $9 \mathrm{Km}$ de dirección NNO a SSE, perteneciente en gran parte al Complejo Alpujárride. En la zona de cabecera dominan los terrenos nevado-filábrides, carac- terizados por un alto grado de metamorfismo: esquistos, micaesquistos, mármoles y cuarcitas (Sierra de los Mayorales). Más al sur aparecen afloramientos de filitas, areniscas metamorfizadas y cuarcitas de tonos rojizos, con intercalaciones de rocas carbonatadas. Entre los terrenos carbonatados dominan las calizas recristalizadas que pasan localmente a mármoles. Cuando éstos alternan con las areniscas y filitas dejan en resalte pequeños escarpes que rompen la monotonía de las formas suaves modeladas en amplias extensiones. Transversalmente al eje principal de la cuenca de las Culebras, en su tramo medio alto, las filitas constituyen la base de las unidades intermedias, en contacto con una formación superior de calizas marmóreas de edad triásica. Puntualmente se observan terrenos yesiferos y de metabasitas. El límite meridional de estas unidades intermedias conecta con terrenos paleozoicos del complejo Alpujárride, compuestos por micaesquistos, cuarcitas, filitas y metaconglomerados (Barranco de los Lobos, Las Zurraderas y el Cambrón). Esta formación se observa también en los desmontes recientemente realizados con motivo de la construcción de la autopista AP-7 Cartagena-Vera. 
Entre las unidades paleozoicas y triásicas se extienden formaciones sedimentarias post-orogénicas de edad pliocena y cuaternaria. El Plioceno aflora especialmente en la parte oriental de la cuenca, donde está representado por arenas y limos amarillentos, areniscas fosiliferas y conglomerados poligénicos de cantos cuarcíticos (IGME, 1974). Éstos últimos pertenecen al Plioceno Superior y forman unidades de glacis o abanicos aluviales, cuya extensión ha sido notablemente reducida por causa de la intensa roturación de tierras practicada en las últimas décadas.

El Cuaternario presenta dos medios de deposición diferentes: uno continental y otro marino. El Cuaternario continental se extiende ampliamente en la parte central de la cuenca, que, durante casi todo este período, ha sido el principal eje de evacuación de los sedimentos generados en la zona alta. A partir de los frentes montañosos la escorrentía torrencial en manto (sheetflows) ha originado extensas deposiciones aluviales en forma de abanicos, sobre los que se ha sobreimpuesto una red de drenaje efímero anastomosado, particularmente dinámico. Las corrientes de avenida circulan a través de ella, bien encauzadas en caso de sucesos menores y moderados (streamflows), o bien provocando desbordamientos e inundaciones (overflows) múltiples en sucesos extremos. El entrecruzamiento de los cauces en los tramos medio e inferior de las ramblas del Renegado y de las Culebras favorecen esta dinámica sedimentaria, provocando un importante aluvionamiento aguas abajo. En los piedemontes de las sierras, colinas y lomas circundantes se desarrollan depósitos coluviales, constituidos por conglomerados heterométricos con cantos de distintas procedencias (cuarcitas, micaesquistos, calizas marmóreas, calcarenitas, etc.) (Arana Castillo et al., 1992).

Al analizar los perfiles longitudinales se obtienen valores de pendiente mayores en los cursos occidentales: Renegado $(5,37 \%)$, Lorquino (4,78 \%), Peña Rubia (4,84\%); mientras que las ramblas de las Culebras y los Quiñoneros parten de cotas más bajas y, pese a la menor longitud, no superan el 3 $\%$ de pendiente. La figura 3 muestra una mayor energía del relieve en el sector noroccidental., que coincide con los intervalos de máxima pendiente. Las zonas más Ilanas quedan interrumpidas con pequeños relieves alomados cuando éstos prevalecen. De hecho, el intenso aprovechamiento agrícola ha llevado a acondicionar el terreno hasta modificar profundamente los rasgos topográficos por debajo de la cota 100 .

\section{CARACTERÍSTICAS HIDROMORFOLÓGICAS DE LA CUENCA DE LAS CULEBRAS}

\subsection{Características generales}

El flujo hídrico temporal está poco canalizado en los tramos no intervenidos por el hombre, de manera que ade- más de producir derrames por desbordamiento al salir del frente montañoso (tipo épandage) suele invadir aguas abajo interfluvios de escasa pendiente. En las zonas más bajas, de menor pendiente y con material suelto, la arroyada adquiere el carácter de flujo laminar (sheetflood) en caso de desbordamiento, dada la amplitud de las llanuras de inundación de las ramblas del Renegado y de las Culebras, ambas directamente conectadas.

La inclinación todavía apreciable de estos Ilanos hacia el mar (no hay que olvidar que se hallan construidos sobre un pseudodelta o abanico aluvial desarrollado a partir del tramo final del trazado de la Rambla del Renegado) proporciona a la corriente de avenida un régimen hidráulico supercrítico (número de Froude> 1).

En cambio, en zonas de mayor pendiente, la escorrentía se concentra y es capaz de incidir enormemente en el terreno originando profundos barrancos. Cuando éstos pierden el encajamiento, normalmente subsecuente a las estructuras, se convierten en cauces de rambla muy abiertos con forma en artesa y en lechos con importante carga tractiva. En el área de estudio no existen grandes diferencias entre barrancos y ramblas desde un punto de vista hidrológico, pero si en función de criterios geomorfológicos. Mientras los primeros poseen mayores tasas de erosión y una escasa ratio anchura/profundidad (inferior a 0,5), las ramblas tienen una fuerte capacidad de transporte y una ratio mayor que 3. El lecho frecuentemente formado por sedimentos gruesos (lecho acorazado) induce a una erosión lateral cuando los márgenes se componen de materiales poco cohesivos.

La escorrentía superficial laminada tiene como consecuencia la formación de extensas y suaves rampas regularmente inclinadas al pie de las laderas (glacis). La acusada regularización de las vertientes montañosas por efecto de los procesos de denudación ha provocado en el área de estudio dos niveles de glacis de acumulación: uno pliocuaternario, preservado gracias a un encostramiento superior, del que apenas quedan restos, y un nivel más reciente y extenso de limos y arenas sobre el que se desarrolla la actual red de drenaje. Las superficies de estos glacis han sido principalmente generadas por coalescencia de los frentes distales de abanicos aluviales, extendidos al pie de las cuencas de recepción de los barrancos y torrenteras. Por lo general., éstos tienen forma de cono truncado con el vértice en el ápice, un perfil transversal convexo y una pendiente inversamente proporcional al radio de curvatura. Su gradiente guarda también relación con la textura de los depósitos, siendo éstos más gruesos en los tramos apicales y particularmente finos en el frente distal del abanico. El perfil longitudinal es cóncavo aguas arriba, pero al alejarse del ápice o zona proximal va adoptando cierta convexidad debido a la mayor acumulación aluvial. Las facies sedimentarias reflejan estructuras tabulares o laminares propias de medios fluviales no confinados. 


\subsection{El sistema de las ramblas del Renegado y de las Culebras}

La cuenca de las Culebras se halla estructurada en una red de cauces de régimen efímero y torrencial que vierte directamente al mar. Su alta pendiente en cabecera confiere a su corriente una fuerte energía y velocidad, generando en época de intensas lluvias escorrentías tipo flash flood.

Como en el resto de la franja costero meridional de la región de Murcia, las ramblas del Renegado y las Culebras son especialmente activas, aunque en este caso pueden actuar de forma conjunta a través de redes poco jerarquizadas. Estas ramblas desembocan directamente en el mar tras salvar un importante desnivel $(400 \mathrm{~m})$ en pocos kilómetros de recorrido (apenas $7 \mathrm{Km}$ ). Cuando sobrevienen avenidas extremas, estas ramblas incrementan su poder erosivo de forma desmesurada, modificando globalmente el sistema fluvial al que pertenecen y creando nuevas formas de depósito (Conesa García, 1995). La torrencialidad con que se producen las precipitaciones y las avenidas en esta zona genera una fuerte erosión del suelo y la liberación de sedimentos que son transportados a través de dichas ramblas. Al igual que en cuencas de cauces efímeros de características aluviales muy similares (Pastrana, Ramonete, Nogalte, Béjar).

\subsubsection{Arrastres torrenciales asociados a una alta capacidad de transporte}

La carga de sedimentos transportada durante las avenidas es muy alta. Destaca el transporte en suspensión que puede significar, en sucesos hidrológicos mayores, más del $20 \%$ del caudal líquido. El transporte de fondo supone la movilización de ingentes cantidades de sedimentos gruesos (arenas, gravas y cantos), que afecta a la totalidad de los tramos de rambla y puede constituir un grave problema para el dimensionamiento de obras de ingeniería hidráulica en la parte inferior de la Rambla de las Culebras.

Estos arrastres, en principio restringidos al interior del cauce en el tramo bajo encauzado de la Rambla de las Culebras, produce en caso de desbordamiento lóbulos de derrame aluvial., compuestos por gravas y arenas gruesas, que por lo general afectan a sectores próximos (diques naturales). En la zona de la llanura de inundación, en cambio, el material depositado se hace progresivamente más fino conforme aumenta la distancia con respecto a los márgenes del cauce, pasando de una textura arenosa a limosa.

A pesar de la intensa abrasión provocada por el choque de arenas y gravas en su desplazamiento por saltación, las partículas del lecho muestran un escaso desgaste, predominando los cantos angulosos y semiangulosos. El carácter turbulento de estas corrientes torrenciales origina una pobre selección de los materiales. El resultado es una mezcla de tamaños con predominio de gravas en las capas superficiales que proporcionan al lecho un aspecto acorazado. La tensión

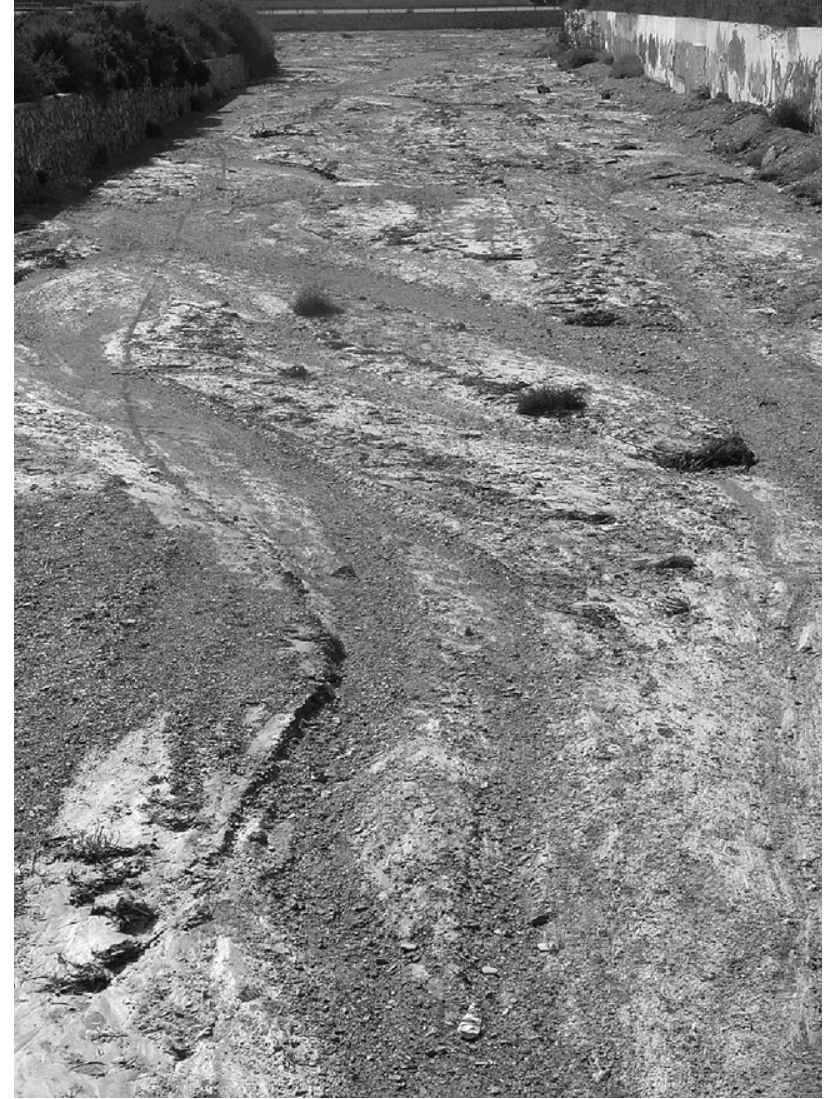

$\Delta$ Figura 4: Cauce braided en el tramo bajo de las Culebras.

crítica opuesta por los materiales de superficie es superior a la de aquellos de capas inferiores, de manera que una vez desmantelados la capacidad de arrastre aumenta considerablemente.

En el área de estudio sólo aparecen barras aluviales en los tramos medios altos de las ramblas del Lorquino y de los Quiñoneros, ya que, al ser éstas utilizadas como caminos en muchos de sus tramos, la modificación antrópica es patente. La creación de las barras es rápida (en un mismo suceso). Southard et al. (1985) proponen una génesis basada en la sucesión de rápidos y pozas, formas que suelen aparecer próximas en lechos con sustrato a poca profundidad o tras un escalón o fuerte cambio de pendiente (tramo alto de la Rambla del Lorquino). Un modelo de cauce asociado al entrecruzamiento y movilidad de este tipo de barras es el cauce braided, caracterizado por barras transversales o diagonales trenzadas, visibles en condiciones de aguas bajas o lecho seco (figura 4). Cuanto más paulatino es el descenso de la avenida más fino es el material depositado en superficie.

\subsubsection{Análisis granulométrico y morfométrico}

Para estimar la capacidad de transporte de la Rambla de las Culebras se han analizado varias muestras del tramo bajo, tanto del cauce como de la llanura de inundación: M1 en el lecho del cauce, M2 en el margen izquierdo, M3 y M4 en la llanura de inundación (Figura 5). 


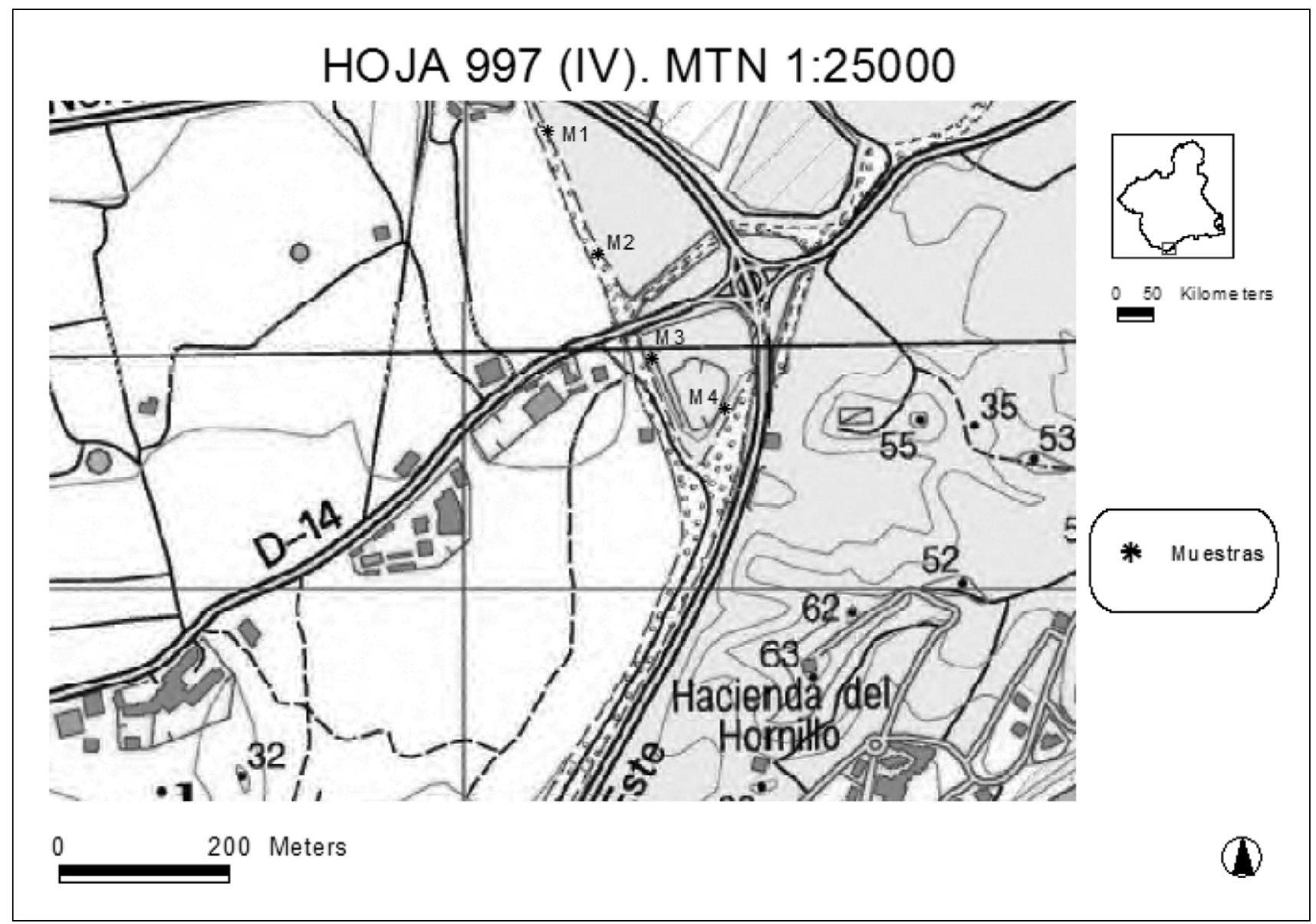

A FiguRa 5: Localización de los puntos de muestreo granulométrico.

De esta forma, se caracterizan los sedimentos expuestos a posibles remociones en caso de avenidas e inundaciones que afecten al entorno del núcleo de Águilas. Los cantos con diámetro superior a $25 \mathrm{~mm}$ han sido seleccionados para el estudio morfométrico (índices de aplanamiento, disimetria y heterometria), mientras que los tamaños d50 y d84de las muestras de limos y arenas se emplean, en relación con los parámetros hidráulicos de la corriente (radio hidráulico, tensión de corte, coeficiente de rugosidad de Manning), para calcular la carga de fondo.

Según se desprende de las curvas granulométricas, las partículas más finas corresponden al punto $\mathrm{M} 4 \mathrm{(d} 50=0,93$ $\mathrm{mm})$, la parte más alejada del cauce en la propia llanura de inundación, mientras que el M1 (lecho del cauce) presenta partículas de un calibre marcadamente superior ( $\mathrm{d} 50=6,48$ $\mathrm{mm}$ ). La llanura de inundación se compone de material más fino, tanto más cuanto más lejos del cauce se halla el punto de muestreo. Los cantos próximos al cauce (lóbulos de derrame o diques naturales) presentan, en cambio, una textura relativamente gruesa ( $\mathrm{M} 3$ tiene una d50 de 5,53 mm).

Respecto a los parámetros morfométricos de los cantos, se observa que el índice de disimetria disminuye conforme decrece el tamaño de aquellos y aumenta la distancia al cauce principal $(0,5)$. Por su parte, el índice de aplanamiento, relacio- nado con el carácter exfoliable de los materiales esquistosos transportados, es más elevado en las partículas sedimentarias del margen izquierdo (M2) $(4,5)$ (Figura 6), lo que indica la presencia en dicha zona de corrientes pretéritas de alta energía. Finalmente, el indice de heterometría de Trask (So), que relaciona los tamaños de las partículas d25 y d75, varía entre 0,41 (M1) y 0,19 (M4). Estos resultados otorgan más homogeneidad, y por tanto mejor selección, a los materiales de la Ilanura aluvial (M3 y M4) frente a los del cauce (M1 y M2).

\subsubsection{Régimen hidráulico y capacidad de transporte de fondo}

A continuación se presentan algunos resultados sobre el transporte de fondo, previa consideración de los parámetros básicos que condicionan el régimen hidráulico. El tipo de régimen hidráulico estimado para radios hidráuli$\cos (\mathrm{Rh})$ de 0,2, 0,5 y $1 \mathrm{~m}$ en el tramo bajo de la Rambla de las Culebras (M1) es supercritico turbulento. Así lo corroboran los números de Reynolds (Re) y de Froude (Fr), que para $\mathrm{Rh}>1 \mathrm{~m}$ superan los valores de $40 \cdot 10^{5}$ y 1,28 respectivamente (Tabla 1). Bajo las condiciones de dicho régimen se explica la presencia de las formas braided observadas en el lecho del cauce principal y la ausencia de formas menores propias de un régimen subcrítico (ripples y dunas). 

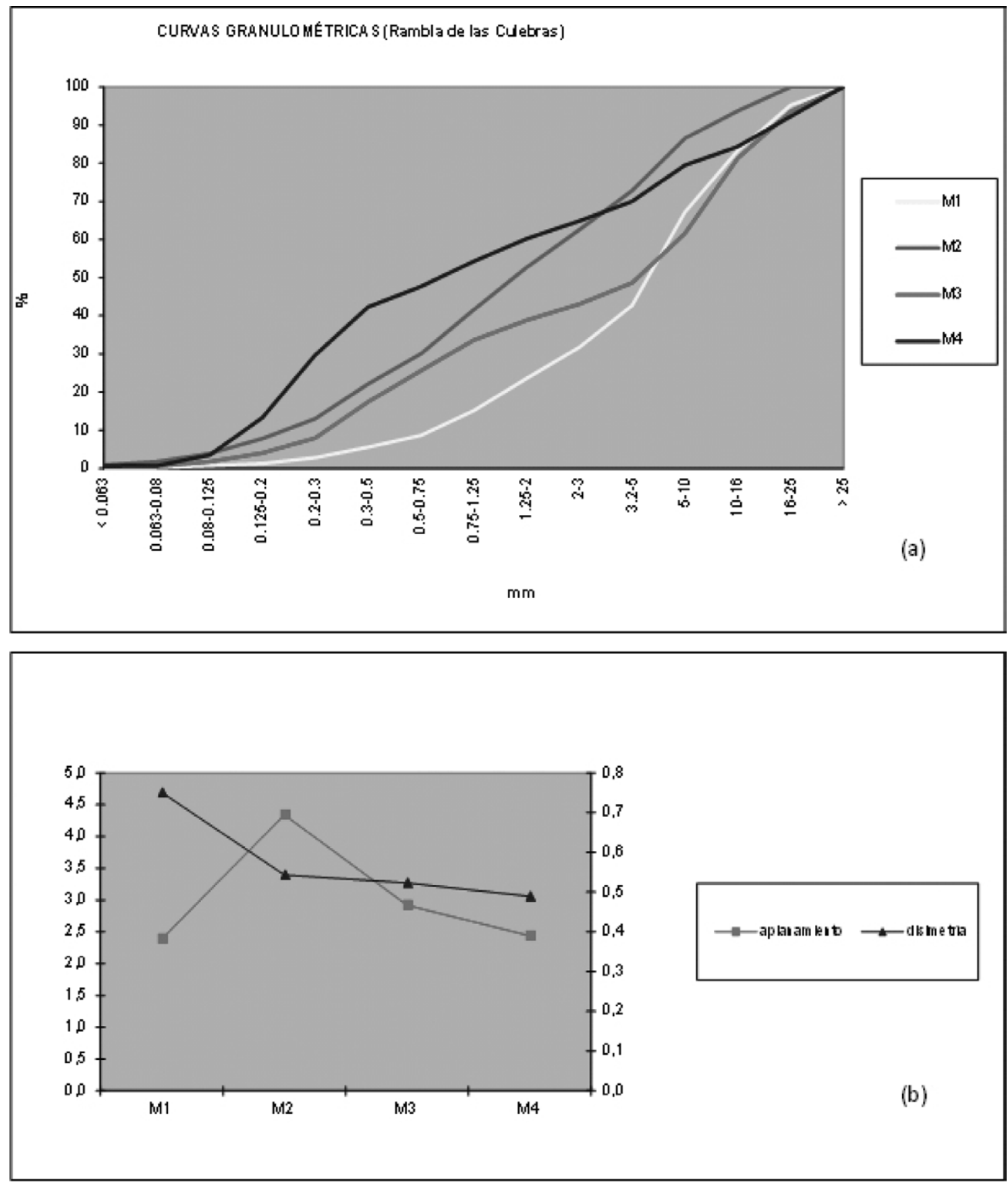

ム FiguRA 6. Distribución de tamaños de los sedimentos (a) e índices de aplanamiento y de asimetría de cantos (b) estimados para las muestras M1, M2, M3 y M4 (tramo bajo de la Rambla de las Culebras).

Para establecer el umbral mínimo de transporte del lecho se ha adoptado el método del inicio de movimiento de Shields. Éste compara dos parámetros hidráulicos que se contrarrestan, y que están muy relacionados con el esquema analógico de Lane. Uno de ellos es la tensión de corte $\left(\tau_{0}\right)$, variable directamente proporcional a la pendiente y el peso específico del agua $(\rho g)$, lo que viene a representar en alguno de los términos a la erosión, la remoción (ecuación 1 ). El otro es la tensión crítica $\left(\tau_{c}\right)$, que es directamente proporcional al peso específico de las partícula sumergidas $\left(\gamma_{c}\right)$-equivalente al peso específico del sedimento $(\gamma s)$ menos el del agua $(\gamma)$ - y al tamaño de la partícula $d_{50}$ (ecuación 2).

$$
\begin{gathered}
\tau_{0}=S \cdot R h \cdot \gamma \\
\tau_{c}=0,056 \cdot \gamma_{s}^{\prime \prime} \cdot d_{50}
\end{gathered}
$$

siendo S la pendiente del lecho (adimensional); Rh, el

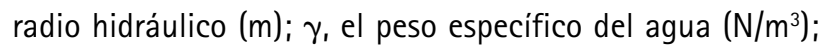
$\gamma_{s}{ }^{\prime}$, el peso específico del sedimento sumergido $\left(\mathrm{N} / \mathrm{m}^{3}\right) ; d_{50}$, el tamaño de la partícula correspondiente a la mediana en la 
distribución granulométrica $(m)$. Los resultados se han contrastado con los valores adimensionales de ambas tensiones y de las partículas, calculadas a partir de las siguientes fórmulas:

$$
\tau_{*}=\frac{\tau_{0}}{\gamma_{s}-\gamma} \cdot d_{50}
$$

donde $\tau_{0}$ es la tensión de corte $\left(\mathrm{N} / \mathrm{m}^{2}\right) ; \gamma_{\mathrm{s}}$ es el peso específico del sedimento $\left(\mathrm{N} / \mathrm{m}^{3}\right) ; \gamma$, el peso específico del agua $\left(\mathrm{N} / \mathrm{m}^{3}\right)$; y $\mathrm{d}_{50}$, el diámetro de la partícula mediana $(\mathrm{m})$.

$$
d_{*}=\left(\frac{(G-1) g}{v^{2}}\right)^{1 / 3} \cdot d_{50}
$$

donde $G$ es la gravedad específica $\left(\gamma_{s} / \gamma\right) ; v$, la viscosidad cinemática $\left(\mathrm{m}^{2} / \mathrm{s}\right) ; \mathrm{g}$, la aceleración de la gravedad $\left(\mathrm{m} / \mathrm{s}^{2}\right)$; $\mathrm{y}_{50}$, el diámetro de la partícula mediana $(\mathrm{m})$.

En las tablas 1 y 2 se muestran los valores de tensión tangencial de corte y tensión crítica estimados para diferente radio hidráulico en el tramo M1 (lecho de rambla), así como los parámetros hidráulicos y granulométricos que intervienen en sus respectivos cálculos. El moderado coeficiente $n$ de Manning obtenido es producto de la combinación de una textura gruesa de los materiales de lecho, la total ausencia de vegetación en los cauces y el trazado poco sinuoso del tramo bajo, lo que, en esta zona, contribuye a alcanzar altas velocidades y una gran turbulencia durante los flujos de avenida ( $\operatorname{Re}>10.000$ y $\mathrm{Fr}>1$ ). Por otra parte, se trata de lechos muy inestables, tal como pone de manifiesto la ratio $\tau_{0} / \tau_{c}$ siempre superior a 1 . Dicha ratio aumenta de forma particularmente sensible conforme se incrementa el radio hidráulico. Al pasar $\mathrm{Rh}$ de 0,2 a $2 \mathrm{~m}$ la ratio se multiplica por 10. Con $\mathrm{Rh}=0,5 \tau_{0} / \tau_{\mathrm{c}}>6$ y con $\mathrm{Rh}=1 \tau_{0} / \tau_{\mathrm{c}}>10$.

La carga de fondo ha sido calculada a partir de las ecuaciones de Duboys, Meyer-Peter Müller y Einstein-Brown. Se trata de fórmulas de capacidad de transporte, o sea permiten estimar la carga máxima posible de acuerdo con los parámetros hidráulicos de la corriente y texturales de los materiales de fondo. Para que la capacidad de transporte coincida con la carga real de sedimentos es necesario que haya material disponible para su movilización. Por otra parte, una verdadera ecuación dinámica contemplaría el régimen no perma-

\begin{tabular}{|c|c|c|c|c|c|c|c|c|c|c|}
\hline $\begin{array}{c}\mathrm{Rh} \\
(\mathrm{m})\end{array}$ & $\mathrm{S}$ & $\mathrm{n}$ & $\begin{array}{c}\mathrm{V} \\
(\mathrm{m} / \mathrm{s})\end{array}$ & $\mathrm{V}$. & $\begin{array}{c}\tau 0 \\
(\mathrm{~N} / \mathrm{m} 2)\end{array}$ & $\tau 0 / \tau \mathrm{c}$ & $\tau$. & $\operatorname{Re}$ & $\operatorname{Re}$. & $\mathrm{Fr}$ \\
\hline 0,2 & 0,0196 & 0,035 & 1,37 & 0,20 & 38,38 & 2,56 & 0,14 & $2,73 \cdot 10^{5}$ & 3245,45 & 0,98 \\
\hline 0,5 & 0,0196 & 0,035 & 2,52 & 0,31 & 95,95 & 6,39 & 0,36 & $12,6 \cdot 10^{5}$ & 5131,51 & 1,14 \\
\hline 1,0 & 0,0196 & 0,035 & 4,00 & 0,44 & 191,89 & 12,78 & 0,72 & $40 \cdot 10^{5}$ & 7257,06 & 1,28 \\
\hline 2,0 & 0,0196 & 0,035 & 6,35 & 0,62 & 383,78 & 25,55 & 1,43 & $127 \cdot 10^{5}$ & 10263,03 & 1,43 \\
\hline
\end{tabular}

A TABla 1. Valores de parámetros hidráulicos estimados para avenidas con distinto radio hidráulico en el tramo M1. Rh = radio hidráulico; $\mathrm{s}=$ pendiente del lecho; $\mathrm{n}=$ coeficiente de rugosidad de Manning; $\mathrm{V}$ = velocidad de la corriente estimada por el método de Manning; V. = velocidad crítica; $\tau 0=$ tensión de corte de la corriente; $\tau 0 / \tau \mathrm{c}=$ ratio entre tensión de corte $\mathrm{y}$ tensión crítica, $\tau$. = tensión de corte adimensional; Re = Número de Reynolds, Re. = Número de Reynold adimensional; Fr = Número de Froude.

\begin{tabular}{|c|c|c|c|c|c|c|}
\hline $\mathrm{d} 16(\mathrm{~mm})$ & $\begin{array}{c}\mathrm{d}_{50} \\
(\mathrm{~mm})\end{array}$ & $\begin{array}{c}\mathrm{d}_{84} \\
(\mathrm{~mm})\end{array}$ & $\mathrm{d}_{\max }(\mathrm{mm})$ & $\mathrm{d}_{\max } / \mathrm{d} 50$ & $\mathrm{~d}_{*}$ & $\begin{array}{c}\tau_{\mathrm{c}} \\
\left(\mathrm{N} / \mathrm{m}^{2}\right)\end{array}$ \\
\hline 1,33 & 6,48 & 16,55 & 38 & 6,05 & 418,65 & 15,02 \\
\hline
\end{tabular}

A TABla 2. Variables utilizadas en el cálculo de la tensión crítica de los materiales granulares del lecho en el tramo M1. d16,d50, d84 = Tamaño de las partículas correspondiente al 16, 50 y 84 centilo del peso de la muestra; $\mathrm{d}_{\max }=$ tamaño máximo de las partículas del lecho; $\mathrm{d}_{\max } / \mathrm{d}_{50}=$ ratio entre el tamaño máximo y el tamaño de la mediana de las partículas; $d .=$ diámetro adimensional de la mediana;

\begin{tabular}{|c|c|c|c|c|c|c|c|c|}
\hline \multirow[b]{2}{*}{ Método } & \multicolumn{2}{|c|}{$\mathrm{Rh}=0,2 \mathrm{~m}$} & \multicolumn{2}{|c|}{$\mathrm{Rh}=0,5 \mathrm{~m}$} & \multicolumn{2}{|c|}{$\mathrm{Rh}=1 \mathrm{~m}$} & \multicolumn{2}{|c|}{$\mathrm{Rh}=2 \mathrm{~m}$} \\
\hline & $\begin{array}{c}q_{b v} \\
\left(\mathrm{~m}^{2} / \mathrm{s}\right)\end{array}$ & $\begin{array}{c}q_{b m} \\
(\mathrm{~kg} / \mathrm{m} \cdot \mathrm{s})\end{array}$ & $\begin{array}{c}q_{b v} \\
\left(\mathrm{~m}^{2} / \mathrm{s}\right)\end{array}$ & $\begin{array}{c}q_{b m} \\
(\mathrm{~kg} / \mathrm{m} \cdot \mathrm{s})\end{array}$ & $\begin{array}{c}q_{b v} \\
\left(\mathrm{~m}^{2} / \mathrm{s}\right)\end{array}$ & $\begin{array}{c}q_{b m} \\
(\mathrm{~kg} / \mathrm{m} \cdot \mathrm{s})\end{array}$ & $\begin{array}{c}q_{b v} \\
\left(\mathrm{~m}^{2} / \mathrm{s}\right)\end{array}$ & $\begin{array}{c}q_{b m c ̧} \\
(\mathrm{~kg} / \mathrm{m} \cdot \mathrm{s})\end{array}$ \\
\hline Duboys & 0,0007 & 0,0020 & 0,0066 & 17,4425 & 0,0289 & 76,572 & 0,1207 & 319,890 \\
\hline Meyer-Peter & 0,0020 & 0,0054 & 0,0119 & 31,4724 & 0,0375 & 99,273 & 0,1116 & 295,681 \\
\hline Einstein-Brown & 0,0010 & 0,0026 & 0,0128 & 33,9084 & 0,0634 & 168,097 & 0,1794 & 475,450 \\
\hline
\end{tabular}
$\tau_{\mathrm{c}}=$ tensión crítica del sedimento del lecho; $\tau_{*_{\mathrm{c}}}=$ tensión crítica adimensional.

$\Delta$ Tabla 3. Transporte de fondo potencial para radios hidráulicos de $0.2,0.5,1$ y $2 \mathrm{~m}$ (M1). 
nente (variable con el tiempo) de agua y de sedimento, así como el desequilibrio en el transporte; es decir, tendría en cuenta la posibilidad de que una corriente transporte más o menos sedimento de fondo del correspondiente a las condiciones de flujo (en este caso, se produciría un cambio de cota de fondo o de pendiente del lecho durante el proceso de transporte). La ecuación de Duboys (5) se basa en la relación entre la tensión límite de corte y el tamaño característico de las partículas:

$$
q_{b v}=\frac{0,173}{d_{s}^{3 / 4}} \tau_{0}\left(\tau_{0}-0,0125-0,019 d_{s}\right)
$$

Donde $q_{b v}$ es la carga unitaria de fondo expresada en volumen $(\mathrm{ft} \cdot / \mathrm{s}) ; \tau_{0}$ es la tensión de corte $\left(\mathrm{lb} / \mathrm{ft}^{2}\right) ; y \mathrm{~d}_{\mathrm{s}}$ el tamaño característico de la muestra $(\mathrm{mm})$. En la ecuación de MeyerPeter Müller (6) intervienen como variables la tensión de corte, la gravedad específica y las tensiones adimensionales, tanto de corte como crítica. Ha sido ensayada, y por tanto se considera válida, para pendientes inferiores al $2 \%$ y para tamaños del material de 0 a $30 \mathrm{~mm}$. Asimismo, se aconseja su uso en corrientes de radio hidráulico menores de $1 \mathrm{~m}$ :

$$
\frac{q_{b v}}{\sqrt{(G-1) g d_{s}^{3}}}=8\left(\tau_{*}-\tau_{* c}\right)^{3 / 2}
$$

siendo $\tau_{*_{1}}$ la tensión de corte adimensional; $\tau_{\mathrm{C}^{*}}$ la tensión crítica adimensional; $g$, la aceleración debida a la gravedad $\left(\mathrm{ft} / \mathrm{s}^{2}\right) ;$ y $\mathrm{d}_{\mathrm{s}}$ el centilo $\mathrm{d}_{84}$ de los tamaños de grano (ft). La ecuación semiteórica de Einstein-Brown (7) incluye un mayor número de términos $y$, a diferencia de las anteriores, está basada en criterios estadísticos:

$q_{b v *}=\frac{q_{b v}}{\omega_{0} d_{s}}=q_{b v}\left(\sqrt{(G-1) g d_{s}^{3}}\left\{\left(\frac{2}{3}+\frac{36 v^{2}}{(G-1) g d_{s}^{3}}\right)-\sqrt{\frac{36 v^{2}}{(G-1) g d_{s}^{3}}}\right\}\right)^{-1}$

donde $\omega_{0} \mathrm{~d}_{\mathrm{s}}$ es la velocidad de caída del agua con sedimentos $\left(\mathrm{ft}^{2} / \mathrm{s}\right) ; \mathrm{g}$, la aceleración por gravedad $\left(\mathrm{ft} / \mathrm{s}^{2}\right) ; \mathrm{d}_{\mathrm{s}}$ el diámetro característico de las partículas (ft); y $v$, la viscosidad cinemática $\left(\mathrm{ft}^{2} / \mathrm{s}\right)$. La capacidad de transporte de fondo estimada para el lecho del tramo bajo de la Rambla de las Culebras (M1), a partir de estos tres métodos, aplicados a avenidas con radio hidráulico $(\mathrm{Rh})$ de $0,2,0,5,1$ y $2 \mathrm{~m}$, se exponen a continuación en la Tabla 3.

Multiplicando la anchura de cauce por el caudal sólido unitario $\left(q_{\mathrm{bv}}\right)$ puede deducirse el caudal total de sedimentos de fondo que las aguas de avenida podrían acarrear en dicho cauce según el radio hidráulico alcanzado. En el lugar donde fue tomada la muestra hay una distancia entre motas de $17 \mathrm{~m}$, lo que indica que el valor unitario de 0,013 $\mathrm{m}^{2} / \mathrm{s}$ (Einstein-Brown, 0,5 m) seria 0,22 $\mathrm{m}^{3} / \mathrm{s}$ de caudal sólido, equivalente a $576,4 \mathrm{~kg} / \mathrm{s}$. Para hallar el caudal líquido se usa la velocidad obtenida a través de la ecuación de Manning:

Conociendo el área mojada (a través del Rh y la anchura) obtenemos un caudal para el ejemplo de $13,11 \mathrm{~m}^{3} / \mathrm{s}$, lo que daría un caudal total de $13,33 \mathrm{~m}^{3} / \mathrm{s}$. Las ecuaciones empleadas difieren en sus resultados en mayor medida cuanto más elevado es el radio hidráulico. Dada la abundancia de gravas en superficie, y el consiguiente acorazamiento del lecho, se ha empleado como tamaño característico de las partículas el centilo $d_{84}$, hecho que resta fiabilidad a la ecuación de Meyer-Peter pierda fiabilidad, sobre todo en avenidas de radio hidráulico superior a $1 \mathrm{~m}$.

\section{CAMBIOS MORFOLÓGICOS EN LA CUENCA Y LA RED DE DRENAJE}

\subsection{Reactivación geomorfológica de las laderas inducida por la acción del hombre}

En las zonas de cabecera los afloramientos rocosos sufren una importante alteración físico-mecánica, asociada a procesos de termoclastia, que dan origen a potentes formaciones detríticas de material suelto. No obstante, en el área de estudio el predominio de formas de relieve suaves, la naturaleza deleznable de los materiales (principalmente esquistos y filitas) y la relativa sujeción del suelo que ejerce la rala vegetación natural hacen que en esta cuenca no abunden taludes activos ni los escarpes desnudos. Ha sido a partir de la intervención humana cuando se ha producido una notable alteración de las laderas.

La intensa roturación de tierras para el aprovechamiento agrícola, el aplanamiento del terreno para la instalación de invernaderos y los desmontes realizados con motivo de la construcción de infraestructuras viarias han hecho aumentar la inestabilidad de las laderas en muchos casos. Claro ejemplo de ello son los deslizamientos de derrubios sueltos o la aceleración de los procesos de erosión en taludes de roca desnuda excavados para el paso de la autopista AP-7 Cartagena-Vera (Figura 7). De hecho, actualmente las laderas más inestables, con mayor número de desprendimientos, corresponden a los tramos de micaesquistos, filitas y areniscas atravesados por dicha infraestructura. Sólo algunos tramos labrados en rocas metamórficas más resistentes (p.e. cuarcitas) muestran cierta estabilidad. Tras el desmonte cuasivertical de estos terrenos es frecuente observar profundos surcos y cárcavas. En tales casos, las laderas conforman un sistema morfogenético especialmente activo, que propicia el desarrollo de extensos depósitos de derrubios sueltos.

En los tramos altos de fácil acceso, como la zona de La Morra del Pan -nacimiento de la Rambla de las Culebras-, se comprueba el abandono de algunos bancales y terrazas de 

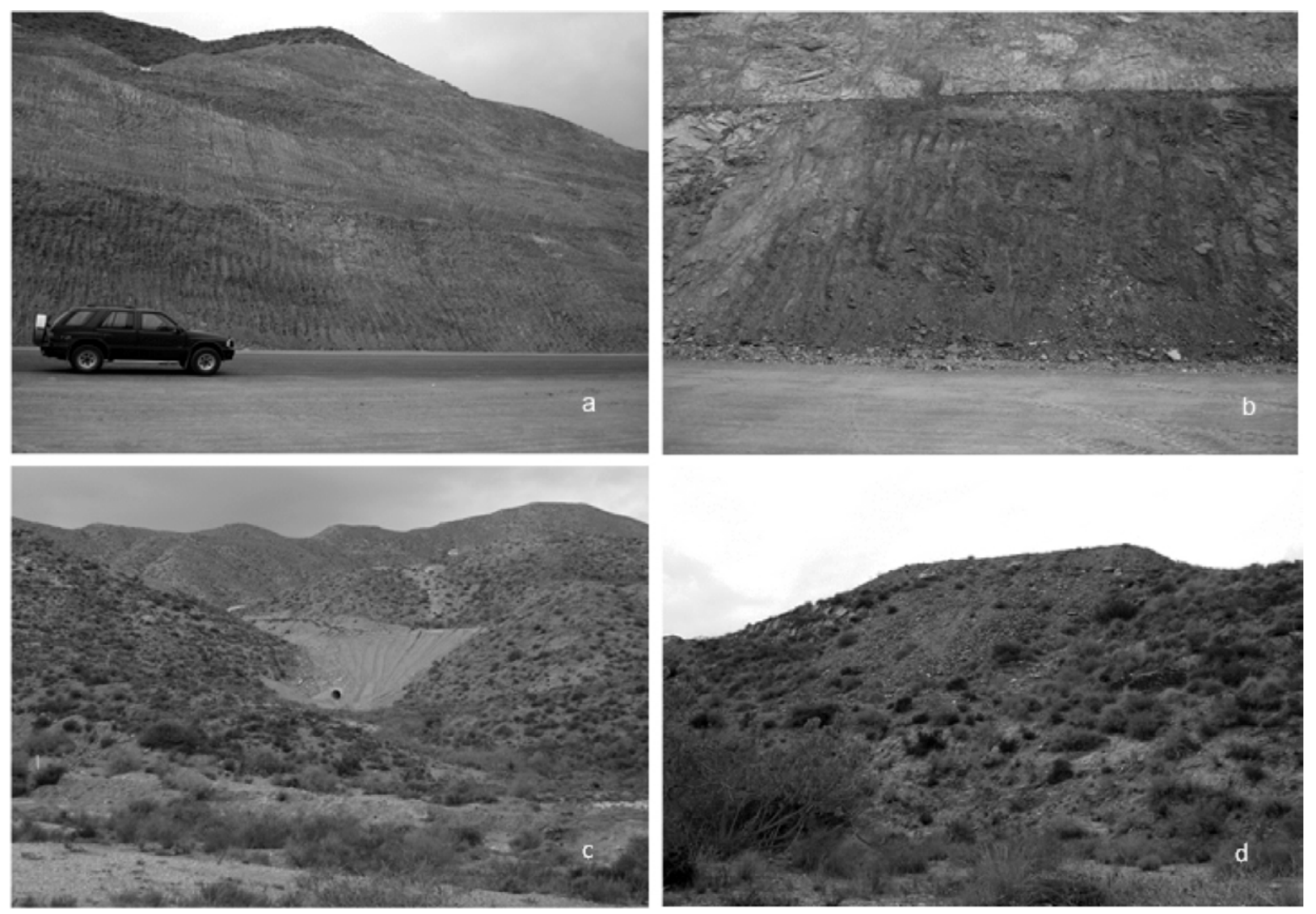

\ Figura 7. Taludes de desmonte (a, b) y terraplén(c) originados por la construcción de la AP-7 Cartagena-Vera; y desprendimiento natural (Rambla de los Quiñoneros) (d).

cultivo delimitadas por muros en precario estado de conservación. Con la actual roturación del terreno y escasa colonización vegetal producida hasta el momento, estos campos abandonados son objeto de erosión y sufren una importante pérdida de suelo. Esto propicia a medio plazo un traslado de material ladera abajo. Dicho material es finalmente removido y transportado por cursos de agua efímeros que adquieren especial torrencialidad en época de avenidas. Sólo asi se explica la clara reactivación geomorfológica que ha experimentado en las últimas décadas el sistema morfogenético fluvial del área, alimentado por una considerable carga de fondo e ingentes volúmenes de sedimentos en suspensión.

\subsection{Modificación de la red de drenaje}

La red de drenaje de la cuenca de las Culebras está integrada por un sistema enmarañado de cauces efimeros que nacen en las sierras litorales al NE del núcleo costero de Águilas (Sierra de los Mayorales, Barranco de los Lobos, Los Peñones, Morra del Pan, entre otros) y desembocan en la Playa de Levante de la citada localidad. Destacan como principales colectores fluviales las ramblas del Renegado y de las Culebras. La primera nace en la Sierra de los Mayorales y recibe por la izquierda los aportes de la Rambla del Lorquino, con origen en el Barranco de los Lobos y cuyo afluente más importante es el Barranco de Peña Rubia. A partir de este punto continúa la Rambla del Renegado en su dirección meridiana encajada entre pequeñas motas de tierra construidas para proteger los cultivos de invernadero. Al llegar a la carretera de circunvalación de Águilas es canalizada paralelamente a su trazado natural hasta confluir con la Rambla de las Culebras. Ésta última nace en la Morra del Pan y, tras recibir por la derecha al Barranco de Tortosa, se une con la Rambla de los Quiñoneros en un tramo medio muy antropizado por el acondicionamiento de terrazas para el cultivo, la instalación de invernaderos y pequeños núcleos de población. Al igual que en la Rambla del Renegado, las motas de tierra que flanquean este curso protegen los invernaderos en un tramo casi rectilíneo hasta la citada confluencia con la Rambla del Renegado.

Se observa en esta área una importante transformación morfológica y de la red de drenaje, puesta claramente de manifiesto en la canalización y desvío de algunos cursos que tiene como objetivo proteger los cultivos y zonas pobladas. En el caso de la Rambla del Lorquino existe una ramificación que en sucesos de fuertes avenidas puede derivar aguas a la Rambla de las Culebras. La finalidad es evitar que la Rambla del Renegado, como cauce más importante y cercano al núcleo de Águilas, no reciba demasiado caudal por parte de su principal tributario (Rambla del Lorquino) y pueda afectar a la circunvalación y a las edificaciones situadas al sur. Esto 
permite laminar las aguas de avenidas extremas y derivar parte del caudal pico hacia la Rambla de las Culebras, desplazando más al este la zona de riesgo de inundación.

Tras el recorrido por la zona de estudio puede comprobarse el intenso impacto antrópico de los últimos decenios, que alcanza tanto a las zonas bajas (tierras de cultivo de invernadero) como a las altas (urbanizaciones, desmontes), sin olvidar las infraestructuras (autopista AP-7 Cartagena-Vera). La comparación de las fotografías aéreas pertenecientes a los vuelos USAF (1956) y SIGPAC (2002) son claro ejemplo de estas transformaciones paisajisticas, donde las formas de relieve y de drenaje han sido particularmente afectadas. A partir de ambas fotografías se observa una neta diferencia entre la red de drenaje existente en 1956, más jerarquizada y densa, y la de 2002, más laxa y simple (figura 8). Incluso, pequeños cerros constatados en la fotografía aérea del vuelo USAF ya no se aprecian en la imagen del SIGPAC, apare- ciendo en su lugar extensas superficies de invernadero; sólo el tramo alto se mantiene similar al de 50 años atrás, con la excepción de la parte afectada por la construcción de la autopista.

En los años previos a la expansión del cultivo de invernadero era muy difícil detectar una jerarquización de la red de drenaje, especialmente por debajo de la isohipsa de 100 $m$. Por encima de ésta se instala una red de barrancos que, al descender de dicha cota, se transforman en cauces de fondo plano con una ratio anchura/profundidad mayor de 3 . Antes de la canalización, los tramos inferiores de estas ramblas afluian a un sector semiendorreico situado en las proximidades septentrionales del núcleo de Águilas. En los tramos intermedios, zonas de gran cambio de pendiente (isohipsas 200-100), los cauces carecian de márgenes definidos, difluyendo alrededor de modestos relieves alomados en su mayor parte residuales (Gil Meseguer, 1987). En la actualidad toda-

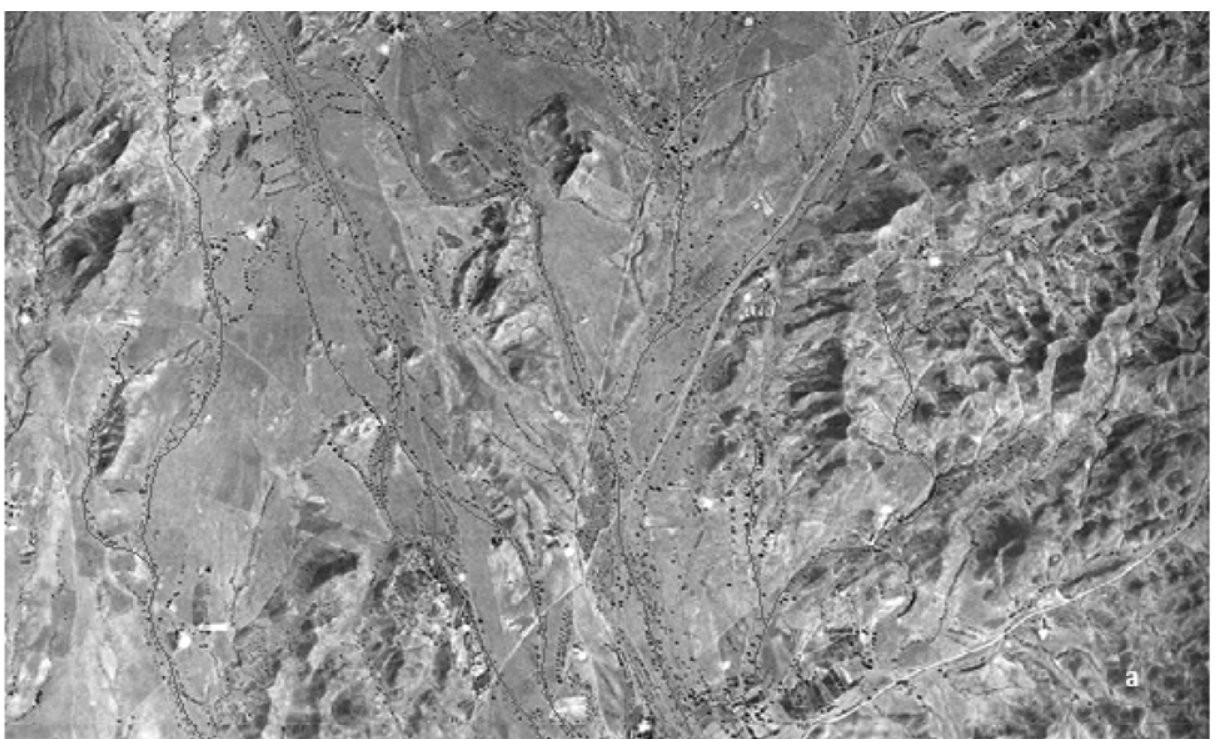

4 Figura 8. Tramo medio de la Rambla de las Culebras, fotografías aéreas del vuelo USAF, 1956 (a) $\mathrm{y}$ del vuelo SIGPAC, 2002 (b).

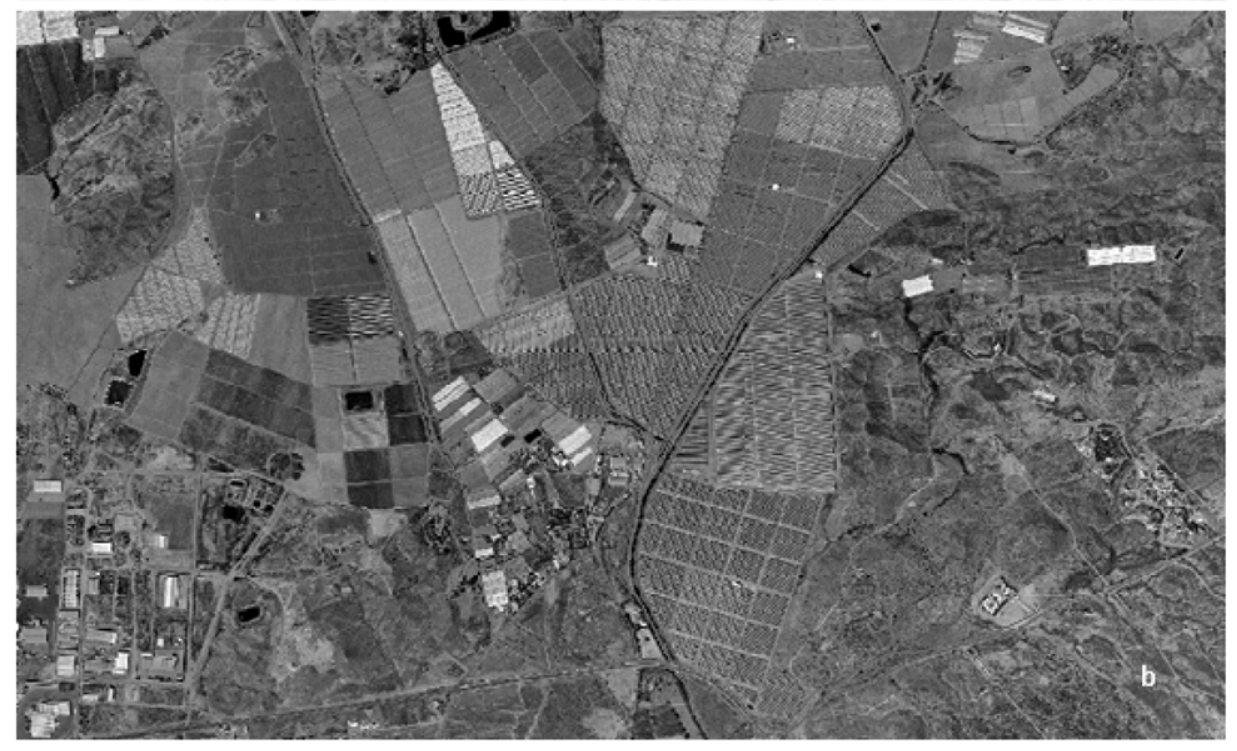



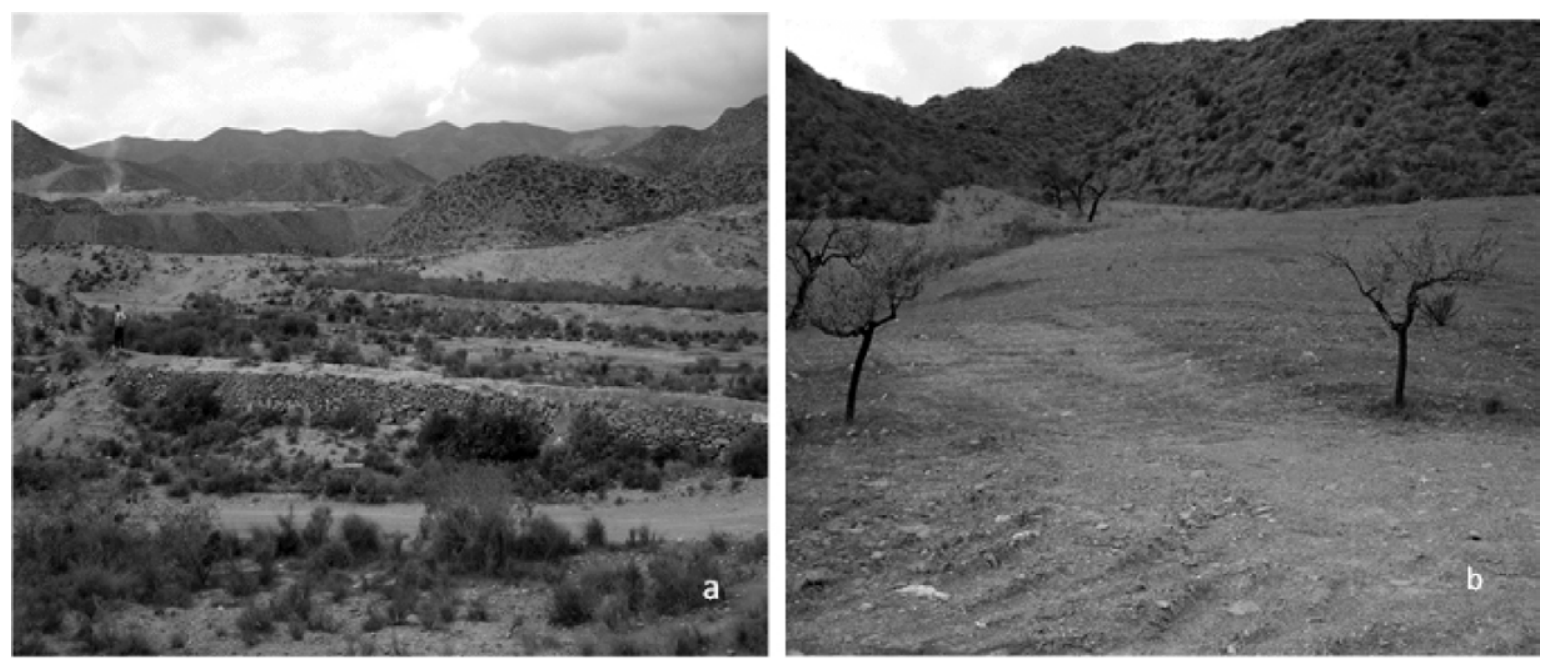

A FiguRa 9. Terraza de cultivo abandonado (tramo medio Lorquino, a) yabanico aluvial (tramo medio Quiñoneros, b).

vía persiste el carácter de depresión en torno a dicho sector, siendo más neto en la parte oriental.

Las Ilanuras de inundación de la parte final de la cuenca han sido aisladas de forma muy significativa, al menos para avenidas con caudal de retorno inferior a 50 años. La mayor profundidad de los nuevos cauces hace menos frecuente la arroyada en manto $y$, en consecuencia, que el agua inunde áreas muy alejadas de los cauces; el principal problema radica, pues, en que los eventos muy importantes de avenida son también más peligrosos por desbordar defensas de una altura considerable (en torno a 3 metros). El encauzamiento de estos tramos ha reducido sensiblemente la probabilidad de desbordamiento y con ello la posibilidad de depositar material fino en la llanura de inundación. La consecuencia más directa es la progresiva acumulación sedimentaria del fondo de la rambla, lo que puede disminuir a su vez la capacidad de desagüe $y$, por tanto, obligar a recrecer las motas y muros de encauzamiento en un plazo medio. El principal problema radica en el riesgo que dicho proceso pueda entrañar ante la ocurrencia de avenidas extremas en un futuro, cuando la confianza en las obras de protección aumente las iniciativas de edificación en el llano de inundación episódico, quedando éste por debajo de la cota del lecho del cauce. Un desbordamiento podrá provocar en tal caso una inundación de magnitud muy superior a las acontecidas hasta ahora.

\section{IMPACTO ANTRÓPICO SOBRE LOS CAUCES Y LECHOS DE INUNDACIÓN}

Su afluente, el Barranco de Tortosa, nace en el mismo puerto que comunica el área de estudio con la Marina de Cope. La existencia de una carretera de cierta entidad (asfaltada y sobre elevada en algunos tramos) paralela a la rambla ha dado protección a pequeños asentamientos de población y terrenos de regadío. En el tramo alto de la Rambla de los
Quiñoneros y del Lorquino, y donde los caminos abandonan el fondo de las ramblas, aparecen formas de lecho de textura gruesa y gran movilidad (barras aluviales longitudinales y centrales), aunque no muy frecuentemente. Siguen apareciendo cultivos abandonados (figura 9) y desmontes hasta que la aparición de motas en las márgenes, conforme se desciende de cota, indica la presencia de cultivos de invernadero.

La expansión de invernaderos es patente en torno a la confluencia de la Rambla de los Quiñoneros con la Rambla de las Culebras (figura 10b), donde se aprecia la inminente puesta en cultivo de un sector de glacis, con la consiguiente remoción de suelo. Esta área recibe los aportes de un tercer curso (afluente de las Culebras por la izquierda), convirtiéndose dicha confluencia en un punto crítico de desbordamiento ante fuertes aguaceros (ITGE, 1975).

En dirección hacia el camino de Venta de Osete, el cauce actual de la Rambla del Renegado es utilizado como camino rural tradicional., dado que el anterior ha sido convertido en terreno agrícola. Aguas abajo, esta rambla atraviesa el camino de Venta de Osete y, a través de un canal de derivación, cruza la carretera de Calabardina a Águilas en dirección a su confluencia con la Rambla de las Culebras. En este tramo, la existencia de muros de cerramiento estrecha considerablemente el cauce y eleva las aguas de avenida a una altura importante.

El paso elevado de la carretera de Circunvalación Norte de Águilas sobre la rambla de las Culebras ofrece una potencial conflictividad por el infradimensionamiento del drenaje transversal a través del desvío (Canal del Renegado) y el aterramiento ejercido por la rambla de las Culebras. En la cuenca vertiente se producen frecuentes movimientos de tierra ocasionados por el acondicionamiento y roturación para el cultivo, la explotación de canteras, los desmontes y taludes por la construcción de caminos y carreteras. Se producen, además, numerosos vertidos de sólidos y obstáculos artificiales (p.e. invernaderos), que pueden actuar como barreras potenciales ante el flujo de grandes avenidas. 

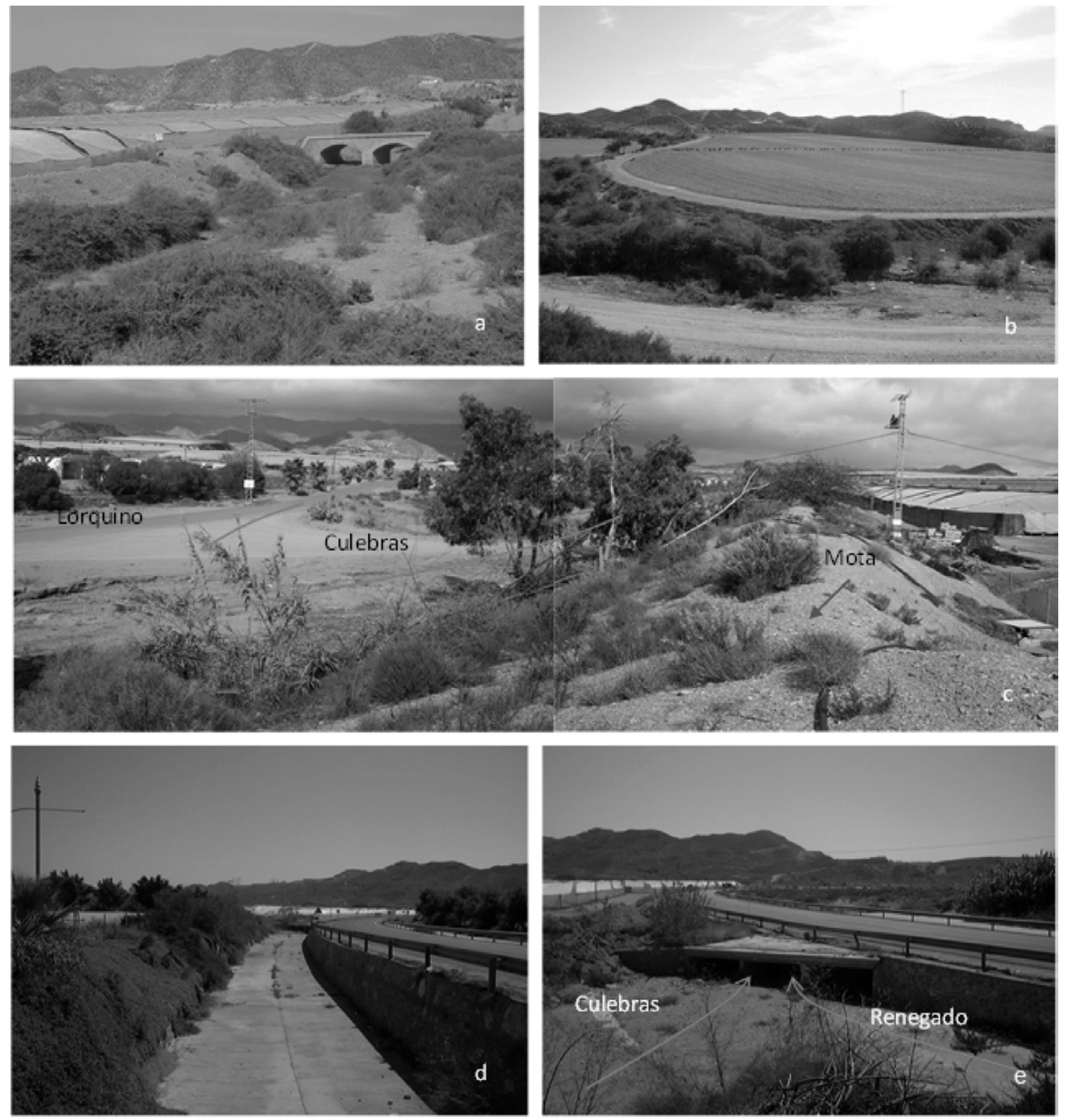

\ Figura 10. Rambla de los Quiñoneros (a); acondicionamiento de una superficie de glacis para el cultivo (b); confluencia de las ramblas de las Culebras y del Lorquino (c); canal de derivación del Renegado (d) y confluencia con la Rambla de las Culebras (e).

A $1,5 \mathrm{~km}$ aguas abajo, la Rambla de las Culebras recibe los aportes de la Rambla del Lorquino a través de uno de sus ramales (figura 10c). Éste es un tramo singularmente peligroso por la existencia de un hotel y algunas viviendas que, aun hallándose detrás de la mota derecha, ocupan el antiguo lecho principal de la Rambla del Renegado. En el tramo inferior ésta última rambla ha sido desviada para que confluya con la de las -Culebras a la altura de la circunvalación de Águilas.

Además de estos dos cauces principales hay que señalar la presencia de un curso secundario que se une a ellos al final de la circunvalación mediante dos ramales artificiales para no afectar a una isleta del vial. Dicho cauce recibe las aguas procedentes del Cambrón, pero su pequeña área de drenaje $\left(2,7 \mathrm{Km}^{2}\right)$ no le permite generar fuertes escorrentías. En esta zona están proliferando pequeñas urbanizaciones, para cuya construcción se realizan importantes movimientos de tierra, lo que hace aumentar las tasas de erosión pese a las poco fructíferas repoblaciones. Los ramales de la derecha atraviesan una serie de abanicos aluviales flanqueados por relieves residuales (Iomas y cerros) con los que conectan a través de suaves taludes de coluviones.

En el tramo final, aguas abajo de la citada confluencia, y próximo a la desembocadura en el mar, aparecen encauzamientos de muro con los que se pretende proteger la carretera y las urbanizaciones que ocupan el llano de episódico de inundación (figura 11d y e). Sin embargo, la acreción sedimentaria del fondo del cauce así confinado 

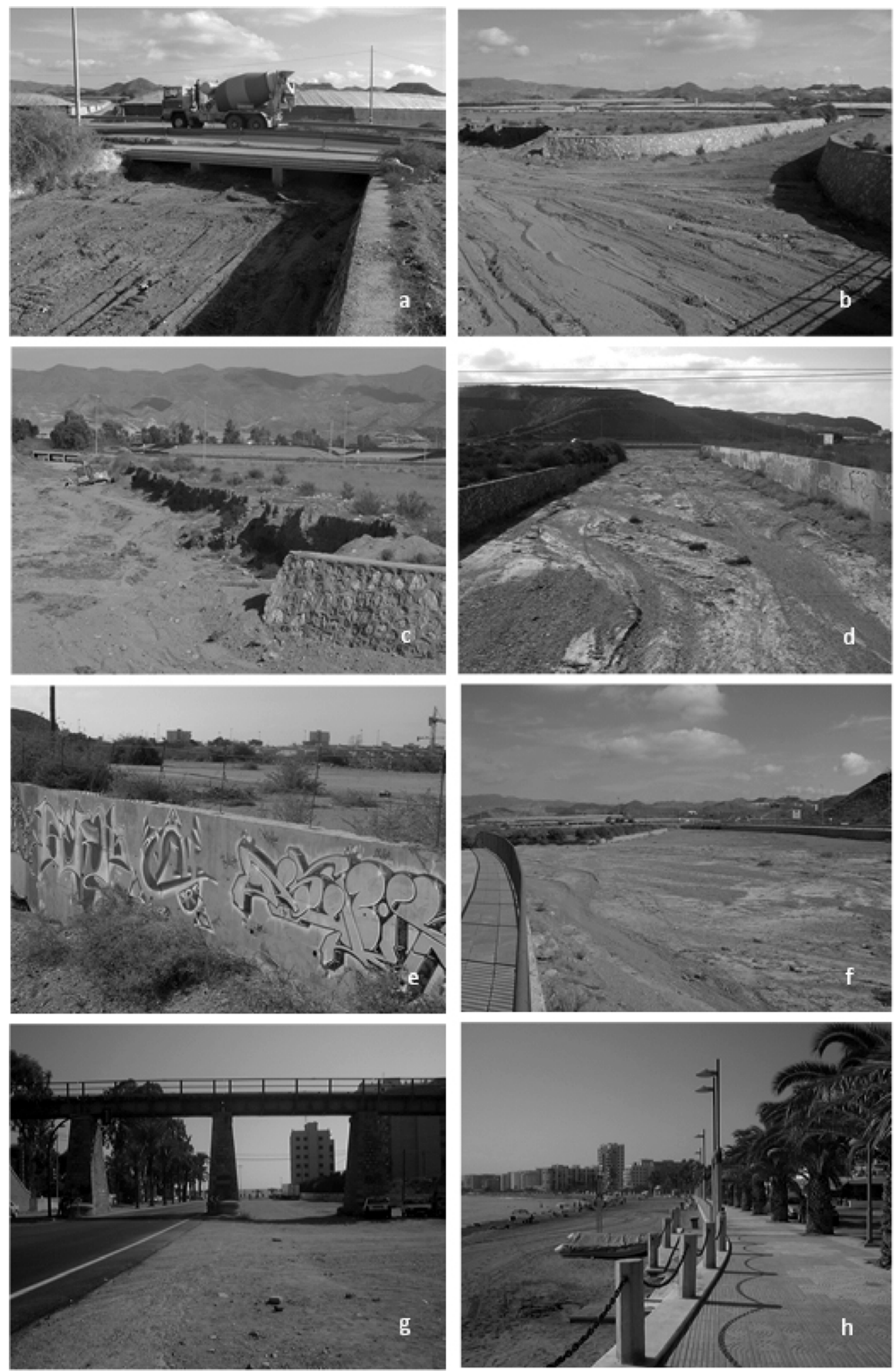

$\Delta$ Figura 11. Canal de derivación del afluente de la Rambla de las Culebras (a) y confluencia de ambos cursos (b); Rambla de las Culebras antes (c) y después (d) del puente de la carretera D-14; muro de protección de urbanización residencial (e) y última confluencia (f); tramo final no encauzadobajo el paso del ferrocarril del Hornillo (g) y desembocadura de la Rambla de las Culebras en la playa de las Delicias (h).

(figura 11c) puede disminuir la capacidad de desagüe a medio plazo y aumentar el grado de vulnerabilidad de los usos del suelo.
El tramo más conflictivo de la Rambla de las Culebras dentro del casco urbano se extiende desde el puente del Hornillo hasta la desembocadura en la Playa de las Delicias 
(figura 11f, g y h), transecto que no está encauzado debidamente y que afecta a viviendas, Paseo Marítimo, carreteras y otras construcciones situadas al mismo nivel que el cauce (el puente del antiguo ferrocarril del Hornillo sería la excepción, aunque el talud del mismo conduce la escorrentía de los ramblizos más occidentales hacia el cauce de las Culebras.

\section{CONCLUSIONES}

La profunda modificación antrópica del sistema fluvial de las Culebras tiene como consecuencia inmediata una rápida respuesta geomorfológica por parte de éste, y, como efecto a medio y largo plazo, una serie de ajustes morfológicos e hidrológicos inducidos, que entrañan una gran peligrosidad y exigen una gestión de dicho espacio más adecuada. El intenso impacto antrópico producido durante las últimas décadas, incluido el debido a la construcción de la autopista AP-7 Cartagena-Vera, afecta muy sensiblemente tanto a las zonas bajas (tierras de cultivo de invernadero) como a las altas (urbanizaciones, desmontes). La comparación de las fotografías aéreas pertenecientes a los vuelos USAF (1956) y SIGPAC (2002) son claro ejemplo de estas transformaciones paisajísticas, donde las formas de relieve y de drenaje han sido particularmente afectadas. La intersección por paso elevado de la carretera de Circunvalación Norte de Águilas sobre la Rambla de las Culebras ofrece un alto grado de conflictividad por la falta de dimensionamiento en las obras del drenaje transversal a través del desvío (Canal del Renegado) y por el aterramiento parcial del cauce debido a una excesiva concentración de sedimentos. Por su parte, el encauzamiento del tramo final, próximo a la desembocadura en el mar, aguas abajo de la confluencia del Canal del Renegado y la Rambla de las Culebras, está provocando una importante acreción sedimentaria del fondo del cauce que conducirá a medio plazo a una neta disminución de su capacidad de desagüe y consiguiente aumento de la probabilidad de desbordamiento. Finalmente, destaca el alto riesgo que presenta el tramo último de la Rambla de las Culebras, extendido dentro del casco urbano desde el puente del ferrocarril hasta la desembocadura en la Playa de las Delicias. Se trata de un tramo de desembocadura, desprovisto de encauzamiento alguno, que afecta a viviendas, Paseo Marítimo y otras infraestructuras construidas al ras del lecho fluvial. Las medidas y actuaciones de concentración del flujo de avenida adoptadas aguas arriba y la falta de protección en el tramo próximo a la desembocadura implican una mayor acumulación de agua y sedimentos en esta zona constituyendo un sector especialmente peligroso para las edificaciones y usos establecidos.

\section{BIBLIOGRAFÍA}

Arana Castillo, R; Rodriguez Estrella, T; Mancheño Jiménez, M.A. y Ortiz SILLA, R. (1992): "Lugares de interés geológico de la Región de Murcia." Agencia Regional para el Medio Ambiente y la Naturaleza. Comunidad Autónoma de la Región de Murcia, Murcia, pp. 163-169.

ChIN, A., GreGoRY, K.J. (2001) "Urbanization and adjustment of ephemeral stream channels." Annals of the Association of American Geographers, 91 (4), pp. 595-608.

CONESA GARCiA, C. (1995): "Torrential Flow Frequency and Morphological Adjustments of Ephemeral Channels in South-East Spain", en E.J. Hickin (Ed.), River Geomorphology, John Wiley \& Sons Ltd, Chichester, ch. 9, 169-192.

- 2003: "Theories and hypothesis of regime applied to the study of dynamic adjustment of alluvial riverbeds." Estudios Geograficos (251), pp. 153-182.

Conesa Garcia, C., Caselles-Miralles, V., Tomas, J.M.S., Garcia-Lorenzo, R. (2010). "Hydraulic geometry, GIS and remote sensing, techniques against rainfall-runoff models for estimating flood magnitude in ephemeral fluvial systems." Remote Sensing, 2 (11), pp. 2607-2628.

COPPUS, R., IMESON, A.C. (2002). "Extreme events controlling erosion and sediment transport in a semi-arid sub-Andean valley." Earth Surface Processes and Landforms 27 (13), pp. 1365-1375.

Domingo, F., Villagarcia, L., Boer, M.M., Alados-Arboledas, L., PuigdefáBREGAS, J. (2001)."Evaluating the long-term water balance of arid zone stream bed vegetation using evapotranspiration modelling and hillslope runoff measurements". Journal of Hydrology, 243 (1-2), pp. 17-30.

DOWNS, P.W. \& GREGORY, K.J. (2004): River channel management. Towards sustainable catchment hydrosystems. Arnold, London.

GIL MESEGUER, E. (1987): Los relieves meridionales. Estudio geográfico de los relieves litorales comprendidos entre la desembocadura del
Río Almanzora (Almería) y la de la Rambla de las Moreras (Murcia). Universidad de Murcia, 254 pp.

GRAF, W.L. (1988): "Definition of floodplains along arid region rivers." Flood Geomorphology, pp. 231-242.

Hooke, J.M., MANT, J.M. (2000). "Geomorphological impacts of a flood event on ephemeral channels in SE Spain." Geomorphology, 34 (3-4), pp. 163-180.

IGME (1974): Memoria del Mapa Geológico de España, 1:50.000, Serie Magna, Hoja N.o 997, Águilas.

ITGE (1995): Atlas Inventario de Riesgos Naturales de la Comunidad Autónoma de la Región de Murcia, Madrid, 138 pp.

Jordan, B.A., Annable, W.K., Watson, C.C., SEN, D. (2010). "Contrasting stream stability characteristics in adjacent urban watersheds: Santa Clara Valley, California." River Research and Applications, 26 (10), pp. 1281-1297.

KHAZAEI, E., SPINK, A.E.F., WO, J.W. (2003). "A catchment water balance model for estimating groundwater recharge in arid and semiarid regions of south-east Iran." Hydrogeology Journal, 11 (3), pp. 333-342.

Kondolf, G. M., PIÉGAY, H. and SEAR, D. (2005) Integrating Geomorphological Tools in Ecological and Management Studies, in Tools in Fluvial Geomorphology (eds G. M. Kondolf and H. Piégay), John Wiley \& Sons, Ltd, Chichester, UK. doi: 10.1002/0470868333.ch21.

LE Houérou, H.N. (1996). "Climate change, drought and desertification." Journal of Arid Environments, 34 (2), pp. 133-185.

Lillo CaRPIO, M. (1988): "Consideraciones sobre los afloramientos tirrenienses detectados entre Cabo Roig (Alicante) y la desembocadura del Río Almanzora (Almería)", Papeles de Geografía, N. ${ }^{\circ}$ 14, pp. 51-82. Universidad de Murcia.

Millán, M.M., Estrela, M.J., Sanz, M.J., Mantilla, E., Martín, M., Pastor, F., Salvador, R., Vallejo, R., Alonso, L., Gangoiti, G., Ilardia, J.L., Navazo, M., Albizuri, A., Artiñano, B., Ciccioli, P., Kallos, G., Carvalho, R.A., Andrés, D.H, Hoff, A., Werhahn, J., Seufert, G., Versino, B. (2005) 
"Climaticfeedbacks and desertification: TheMediterraneanmodel." Journal of Climate, Volume 18, Issue 5, 684-701.

Nachtergaele, J., Poesen, J. (2002). "Spatial and temporal variations in resistance of loess-derived soils to ephemeral gully erosion." European Journal of Soil Science, 53 (3), pp. 449-463

Oostwoudwisdenes, D.J., Poesen, J., Vandekerckhove, L., Ghesouiere, M. (2000)."Spatial distribution of gully head activity and sediment supply along an ephemeral channel in a Mediterranean environment." Catena 39 (3), pp. 147-167.

ORTEGA, J.A., GaRZÓNHEYDT, G. (2009) "Geomorphological and sedimentological analysis of flash-flood deposits. The case of the 1997 RiviIlasflood (Spain)."Geomorphology, 112 (1-2), pp. 1-14.

Poesen, J., Nachtergaele, J., Verstraeten, G., Valentin, C. (2003). "Gully erosion and environmental change: Importance and research needs." Catena 50 (2-4), pp. 91-133.

Puigdefabregas, J., Sole, A., Gutierrez, L., del Barrio, G., Boer, M. (1999). "Scales and processes of water and sediment redistribution in drylands: Results from the Rambla Honda field site in Southeast Spain." Earth Science Reviews, 48 (1-2), pp. 39-70.

Qu, Y., DufFY, C.J. (2007). "A semidiscrete finite volume formulation for multiprocess watershed simulation." Water Resources Research, 43 (8), art. n. ${ }^{\circ}$ W08419

RozIN, U., ScHICK, A.P. (1996). "Land use change, conservation measures and stream channel response in the Mediterranean/semiarid transition zone: NahalHoga, southern Coastal Plain, Israel." IAHS-AISH Publication,236, pp. 427-444.

SÁnCHEZ, J.A, ARTÉs, F., FRESNEDA, V.S. (1979): "Aplicación científica de las fotografías de la superficie terrestre obtenidas mediante satélites artificiales. Arcos montañosos del litoral mediterráneo entre Sierra de Almagrera (Almeria) y Mazarrón (Murcia)." Tecniterrae, n. ${ }^{3}$ 31, pp. 21-37.

ShieldS, F.D., CoOpeR Jr., C.M., KNIGHT, S.S., Moore, M.T. (2003). "Stream corridor restoration research: A long and winding road." Ecological Engineering, 20 (5), pp. 441-454. 